\title{
A Case with Primary Aldosteronism Due to Unilateral Multiple Adrenocortical Micronodules
}

\author{
YUKI HIRONO, MASARU DOI, TAKANOBU YOSHIMOTO, KAZUO KANNO*, YOSHIRO HIMENO**, \\ KAZUHIRO TAKI***, HIRONOBU SASANO* AND YUKIO HIRATA \\ Department of Clinical and Molecular Endocrinology, Tokyo Medical and Dental University Graduate School, Tokyo 113-8519, Japan \\ * Department of Internal Medicine, Musashino Red Cross Hospital, Musashino 180-8610, Japan \\ **Department of Radiology, Musashino Red Cross Hospital, Musashino 180-8610, Japan \\ ***Department of Pathology, Musashino Red Cross Hospital, Musashino 180-8610, Japan \\ \#Department of Anatomic Pathology, Tohoku University Graduate School of Medicine, Sendai 980-8575, Japan
}

\begin{abstract}
A 46-year-old male with long-term treatment-resistant hypertension and past history of cerebral hemorrhage was found to have suppressed plasma renin activity (PRA) and normal plasma aldosterone concentration (PAC) with aldosterone/renin ratio of 25.3. Furosemide plus upright test did not stimulate PRA, but computed tomography scan of the abdomen revealed no abnormal lesions in either adrenal gland. Selective adrenal venous sampling (SAVS) showed that PAC in the left and the right adrenal vein were $1000 \mathrm{ng} / \mathrm{dl}$ and $230 \mathrm{ng} / \mathrm{dl}$, respectively, which increased to $1500 \mathrm{ng} / \mathrm{dl}$ and $620 \mathrm{ng} / \mathrm{dl}$, respectively, after ACTH stimulation. Diagnosis of primary aldosteronism due to hypersecretion of aldosterone from the left adrenal gland was made, and laparoscopic left adrenalectomy was performed. Pathological examination of the 'apparently normal' adrenal tissue resected revealed the presence of poorly encapsulated multiple adrenocortical micronodules which showed positive immunoreactivity for $3 \beta$-hydroxysteroid dehydrogenase by immunohistochemical study, but negative immunoreactivity in the hyperplastic zona glomerulosa consistent with paradoxical hyperplasia associated with primary aldosteronism. Postoperatively, PRA was normalized and his high blood pressure was well controlled with lower doses of antihypertensive drugs than those used before surgery. The clinicopathological features of our case are consistent with the diagnosis of unilateral multiple adrenocortical micronodules (UMN), a new subset of primary aldosteronism, in which SAVS proved to be a useful diagnostic tool for its localization.
\end{abstract}

Key words: Primary aldosteronism, Unilateral multiple adrenocortical micronodules (UMN), Selective adrenal venous sampling, 3 $\beta$-Hydroxysteroid dehydrogenase

(Endocrine Journal 52: 435-439, 2005)

RECENTLY, an increasing body of evidence suggests that aldosterone is an independent risk factor for cardiovascular disease based on many clinical and experimental studies [1-5]. Growing lines of evidence have consistently supported the view that secondary hypertension due to primary aldosteronism is much more frequent (8-20\%) than previously suspected [6-10]. It is important to diagnose primary aldosteronism during

Received: December 16, 2004

Accepted: April 21, 2005

Correspondence to: Yukio HIRATA, M.D., Department of Clinical and Molecular Endocrinology, Tokyo Medical and Dental University Graduate School, 1-5-45 Yushima, Bunkyo-ku, Tokyo 113-8519, Japan the early stage before the progression to end-organ damage because primary aldosteronism due to unilateral adrenal lesion, mostly aldosterone-producing adenoma, can be cured by surgery [11]. On the other hand, it is difficult to detect small adrenal lesions, such as microadenomas, micronodules and hyperplasia, by standard imaging tests, such as CT scan.

We herein describe a case with primary aldosteronism without adrenal mass or hyperplastic lesion on CT scan, who showed aldosterone hypersecretion in the left adrenal vein before and after stimulation with ACTH by selective adrenal venous sampling (SAVS), and was found to have unilateral multiple adrenocortical micronodules in the left adrenal gland after surgery. 


\section{Case Report}

A 46-year-old male was referred to Musashino Red Cross Hospital because of drug-resistant hypertension on October, 2002. He was pointed out high blood pressure in his twenties. He had putamen hemorrhage at the age of 41. Although he took multi-antihypertensive drugs (nifedipine $40 \mathrm{mg}$, betaxolol $20 \mathrm{mg}$, doxazosin $4 \mathrm{mg}$ ), his blood pressure remained uncontrolled (126142/94-110 mmHg).

He was $167.5 \mathrm{~cm}$ tall, and weighed $79.2 \mathrm{~kg}$. Blood pressure was $142 / 110 \mathrm{mmHg}$. Except for mildly low serum potassium level $(3.6 \mathrm{mEq} / \mathrm{l})$, biochemical parameters were otherwise all within the normal ranges. Echocardiography revealed borderline left ventricular hypertrophy and normal ejection fraction (68\%). Funduscopic examination showed mild hypertensive change. Urinalysis was normal and creatinine clearance was $85.5 \mathrm{ml} / \mathrm{min}$. Endocrine data (Table 1) showed that PRA $(0.3 \mathrm{ng} / \mathrm{ml} / \mathrm{hr})$ was suppressed, but PAC was normal $(7.6 \mathrm{ng} / \mathrm{dl})$ with aldosterone/renin ratio (ARR) of 25.3. Plasma levels of ACTH, cortisol and catecholamines were all within normal range. PRA remained suppressed $(0.8 \mathrm{ng} / \mathrm{ml} / \mathrm{hr})$ and PAC was $14 \mathrm{ng} / \mathrm{dl}$ after stimulation with furosemide $(40 \mathrm{mg})$ plus upright posture for 2 hours, suggesting the autonomous secretion of aldosterone. CT scan of the abdomen revealed no abnormal lesions in either adrenal gland (Fig. 1). The diagnosis of primary aldosteronism due to idiopathic hyperaldosteronism (IHA) was most likely based on clinical and endocrine data with negative adrenal lesions by CT scanning, which prompted us to perform selective adrenal venous sampling (SAVS).

Table 1. Endocrine Data

\begin{tabular}{llll}
\hline Plasma ACTH $(\mathrm{pg} / \mathrm{ml})$ & $23.9(7.4-55.7)$ \\
Plasma cortisol $(\mu \mathrm{g} / \mathrm{dl})$ & $15.0(4.0-18.3)$ \\
PRA $(\mathrm{ng} / \mathrm{ml} / \mathrm{hr})$ & $0.3(0.3-2.9)$ & \\
PAC $(\mathrm{ng} / \mathrm{dl})$ & $7.6(29.9-159)$ & \\
aldosterone/renin ratio (ARR) & 25.3 & & \\
Plasma adrenalin $(\mathrm{pg} / \mathrm{ml})$ & $46(<100)$ & \\
Plasma noradrenalin $(\mathrm{pg} / \mathrm{ml})$ & $402(100-450)$ & \\
Plasma dopamine $(\mathrm{pg} / \mathrm{ml})$ & $11(<20)$ & \\
\hline Furosemide plus upright test & 0 & 120 & $(\mathrm{~min})$ \\
PRA $(\mathrm{ng} / \mathrm{ml} / \mathrm{hr})$ & 0.4 & 0.8 & \\
PAC $(\mathrm{ng} / \mathrm{dl})$ & 9.3 & 14 & \\
\hline
\end{tabular}

(numbers in parentheses: Reference values)
PAC and plasma cortisol levels in adrenal venous effluents obtained by SAVS before and after ACTH stimulation are shown Fig. 2. Basal aldosterone levels in right and left adrenal vein were $230 \mathrm{ng} / \mathrm{dl}$ and $1000 \mathrm{ng} / \mathrm{dl}$, respectively, which rose to $620 \mathrm{ng} / \mathrm{dl}$ and $1500 \mathrm{ng} / \mathrm{dl}$, respectively, $30 \mathrm{~min}$ after stimulation with ACTH (Cortrosyn ${ }^{\circledR}: 250 \mu \mathrm{g}$ ). The data obtained from SAVS strongly suggested preferential aldosterone hypersecretion from the left adrenal gland. After obtaining informed consent for adrenal surgery, the left

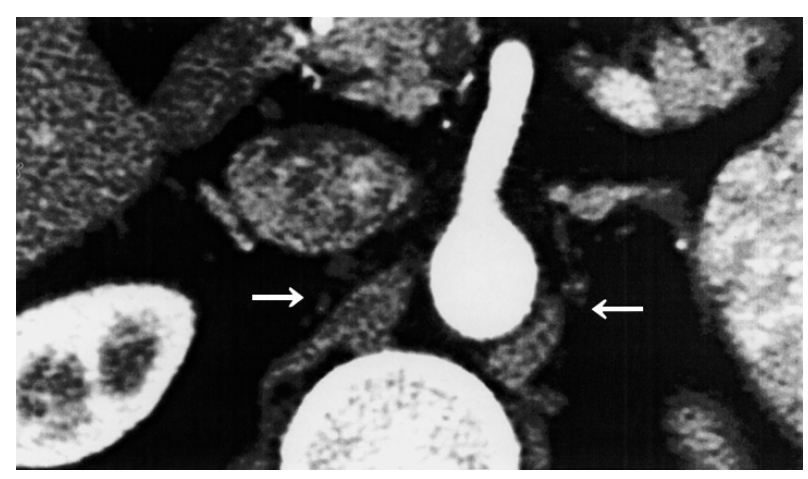

Fig. 1. CT scan of the abdomen. Arrows indicate 'apparently normal' adrenal glands.

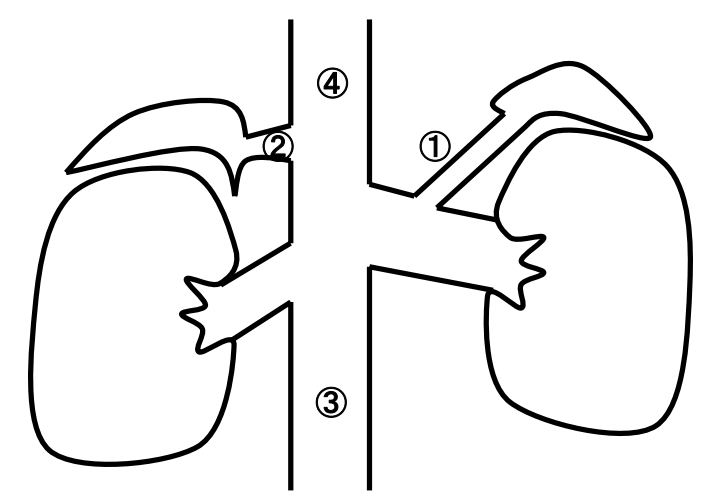

\begin{tabular}{|lc|c|c|}
\hline \multicolumn{2}{|c|}{ PAC $(\mathrm{ng} / \mathrm{dl})$} & $\mathrm{F}(\mu \mathrm{g} / \mathrm{dl})$ & $\mathrm{PAC} / \mathrm{F}$ \\
\hline (1) $1000 / 1500$ & $600 / 785$ & $1.67 / 1.91$ \\
\hline (2) & $230 / 620$ & $274 / 358$ & $0.84 / 1.73$ \\
\hline (3) 12 & 20.5 & 0.59 \\
\hline (4) 20 & 24.8 & 0.81 \\
\hline
\end{tabular}

Fig. 2. Selective adrenal venous sampling. Plasma aldosterone concentration (PAC), cortisol (F), and the ratios of PAC/F in (1) left adrenal vein, (2) right adrenal vein, (3) inferior vena cava, (4) superior vena cava, are shown before and after stimulation with ACTH. 
adrenal gland was surgically resected. Postoperative course was uneventful. PRA $(1.7 \mathrm{ng} / \mathrm{ml} / \mathrm{hr})$ and serum $\mathrm{K}$ level $(4.2 \mathrm{mEq} / \mathrm{l})$ were normalized and PAC was $9.3 \mathrm{ng} / \mathrm{dl}$ with ARR of 5.5. The dose of antihypertensive drug was reduced (nifedipine $20 \mathrm{mg}$, betaxolol $10 \mathrm{mg}$ ), and blood pressure was well controlled (124/ $80 \mathrm{mmHg})$.

\section{Pathological Examination}

On gross examination, the left adrenal gland was 'apparently normal', $6.7 \times 3.5 \times 1.0 \mathrm{~cm}$ in size, weighing $8.6 \mathrm{~g}$. However, multiple micronodules ranging up to

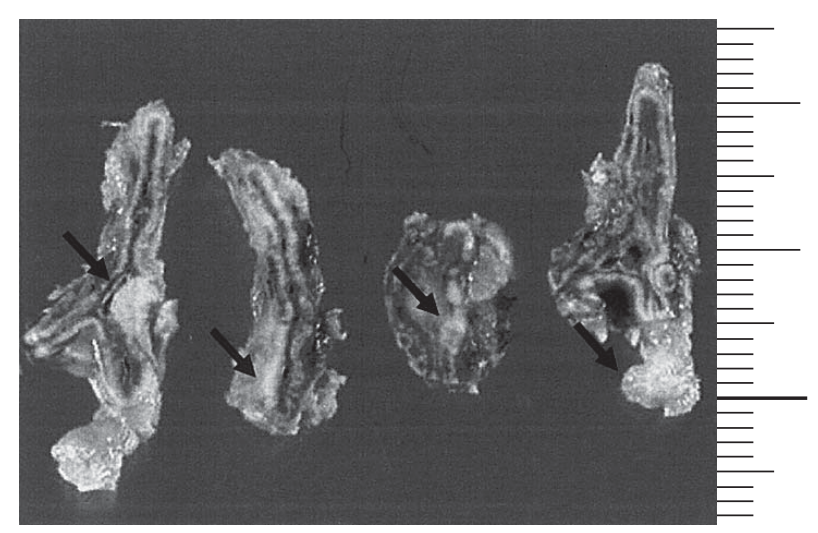

Fig. 3. Gross appearance of the resected left adrenal gland. Multiple small nodules were noted on the several cut surfaces of the adrenal tissue.

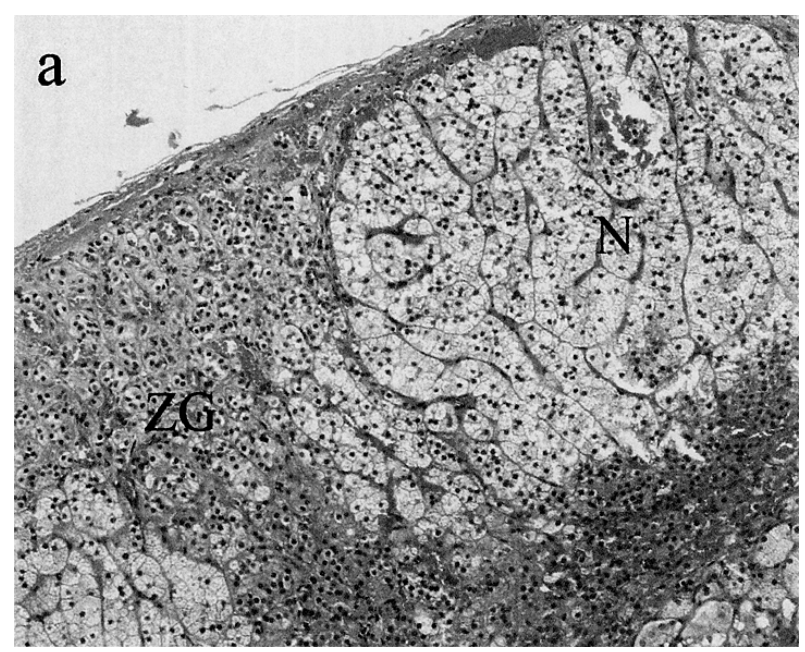

$5 \mathrm{~mm}$ in greatest dimension were noted on the several cut surfaces of the resected adrenal tissue (Fig. 3).

Histological examination demonstrated the presence of poorly encapsulated multiple adrenocortical micronodules in the sections of the adrenal gland, composed of both compact and clear cells, the latter being predominant, and hyperplasia of the zona glomerulosa was detected in the non-nodular region (Fig. 4a). Immunohistochemical analysis of $3 \beta$-hydroxysteroid dehydrogenase (3 $\beta$-HSD) [12] showed positive immunoreactivity for $3 \beta-\mathrm{HSD}$ in cortical cells of the nodules (Fig. 4b), whereas negative for $3 \beta$-HSD in hyperplastic zona glomerulosa cells, compatible with paradoxical hyperplasia associated with hyperaldosteronism [13]. These data are consistent with the notion that the cortical cells of micronodules actively synthesize aldosterone, but the hyperplastic zona glomerulosa cells do not.

\section{Discussion}

We present here a rare case of primary aldosteronism due to UMN as originally reported by Omura et al. [14]. The diagnosis of primary aldosteronism in the present case was most likely because of suppressed PRA with relatively high ARR $[15,16]$ and its failure to rise after stimulation with furosemide-upright position. Although his serum potassium level was low

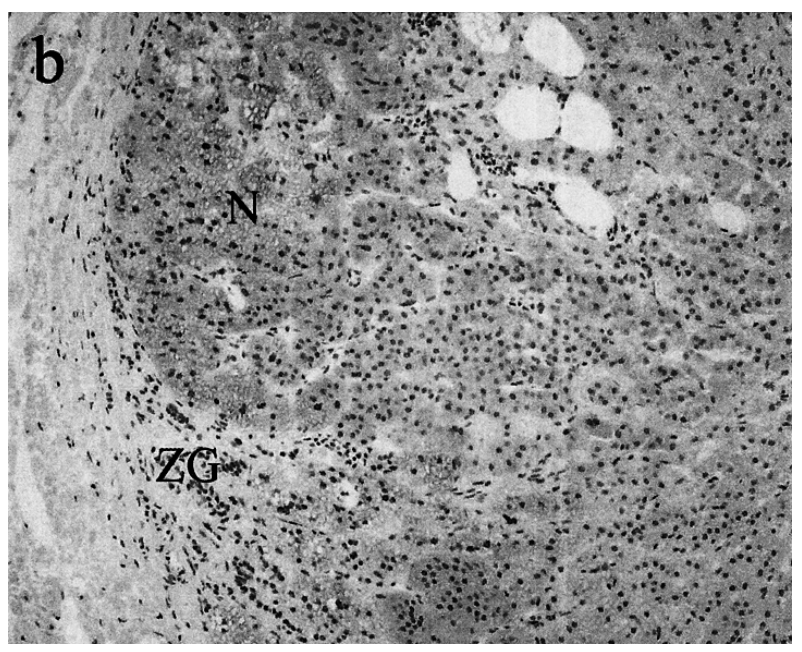

Fig. 4. Microscopic examination of left adrenal gland.

(a) adrenocortical micronodule (N) surrounded by hyperplastic zona glomerulosa (ZG) cells (HE, $\times 100)$, (b) immunohistochemistry; the cortical cells of the nodules $(\mathrm{N})$ showed positive immunostaining for $3 \beta-\mathrm{HSD}$, but hyperplastic zona glomerulosa $(\mathrm{ZG})$ cells were negative $(\times 100)$. 
normal, only a small population (9-37\%) of primary aldosteronism from medical centers from five continents has recently been reported to be hypokalemic [17]. In fact, Omura et al. have also reported that hypokalemia $(<3.3 \mathrm{mEq} / \mathrm{l})$ was found in only one-quarter of the 61 patients with primary aldosteronism [10]. Our patient had been hypertensive since his twenties with past history of putamen hemorrhage, and his hypertension was poorly controlled with multiantihypertensive drugs. However, he had no obvious adrenal lesions by adrenal CT scan. In order to localize the source of hypersecretion of aldosterone in patients with primary aldosteronism without obvious adrenal lesions by standard imaging tests, SAVS is highly recommended $[14,20]$.

Our patient showed hypersecretion of aldosterone from the left adrenal gland because of the greater lateralized ratio of PAC (left /right: 4.3) and the greater PAC $(1500 \mathrm{ng} / \mathrm{dl})$ in the left adrenal vein after ACTH stimulation. The diagnosis of IHA could be excluded because PAC was comparable in both adrenal veins. The laterality of PAC, as demonstrated in our case, strongly suggests that the left adrenal gland was responsible for the abnormal aldosterone hypersecretion. Although the resected left adrenal gland was 'apparently normal', histopathologic and immunohistochemical analysis established the diagnosis of UMN as originally reported by Omura et al. [14]. The left adrenal gland contained small, poorly encapsulated multiple cortical nodules, distinct from well-encapsulated adenoma. Furthermore, immunohistochemical study revealed positive immunoreactivity for $3 \beta-\mathrm{HSD}$ in cortical cells of these micronodules, but negative immunoreactivity in the hyperplastic zona glomerulosa. These histopathological and immunohistochemical features were all compatible with those of UMN [14].

The diagnosis of primary aldosteronism due to unilateral adrenal pathology, including unilateral adrenal hyperplasia (UAH), UMN, and microadenoma (less than $6 \mathrm{~mm}$ in size), is clinically important but difficult to localize with the diagnostic imaging tests, such as CT scan. Therefore, patients with UMN may be misdiagnosed as either low-renin essential hypertension or IHA, and treated with antihypertensive drugs for long-term periods as in the present case. Distinct from IHA, hypertension caused by UMN apparently responds to unilateral adrenalectomy [14]. His preoperative treatment-resistant hypertension was well controlled by reduced doses of antihypertensive drugs after removal of the affected left adrenal gland. Since he had a long history (more than 20 years) of hypertension and the recent history of putamen hemorrhage, the failure of complete normalization of blood pressure after surgery could be accounted for by aldosterone-induced and/or hypertension-induced end-organ damage $[18,19]$.

SAVS should be performed in those patients with primary aldosteronism with 'apparently normal' adrenal glands on CT scan to determine whether hypersecretion of aldosterone is from unilateral or bilateral source $[20,21]$. If it is bilateral, the diagnosis of IHA is made with first line of medical treatment using aldosterone receptor antagonists in combination with or without other antihypertensive drugs. If it is unilateral, the diagnosis of unilateral adrenal pathology including UMN, UAH and microadenoma, is most likely, and surgical treatment (unilateral adrenalectomy) is recommended.

The significance of ACTH stimulation in the correct lateralization of unilateral adrenal pathology remains open to question. Previous reports have recommended ACTH stimulation during SAVS to minimize the pulsatile variation in aldosterone release $[22,23]$. Contrary to these reports, Magill et al. have reported that ACTH stimulation did not significantly improve the diagnostic accuracy during SAVS [24]. ACTH stimulation in our case did not increase the lateralized ratios (dominant to nondominant PAC and normalized PAC). Our data are consistent with those of Tanabe et al. who reported that the lateralized ratios were unchanged or even decreased after ACTH stimulation during SAVS in most patients with primary aldosteronism [25]. In contrast, the absolute value of PAC $(1500 \mathrm{ng} / \mathrm{dl})$ in the left adrenal vein after ACTH stimulation in our case is consistent with the diagnosis of aldosterone hypersecretion (more than $1400 \mathrm{ng} / \mathrm{dl}$ ) as proposed by Omura et al. [10]. Thus, further studies are needed to establish the significance of ACTH stimulation during SAVS for the improvement of diagnostic accuracy in localization of primary aldosteronism.

In conclusion, our male patient is the fifth case of primary aldosteronism due to UMN thus far reported, in which SAVS proved to be a useful diagnostic tool for its localization. However, a long-term follow-up is needed to observe whether or not aldosterone hypersecretion may recur from the 'apparently normal' adrenal gland left intact. 


\section{References}

1. Rocha R, Stier CT Jr (2001) Pathophysiological effects of aldosterone in cardiovascular tissues. Trend Endocr Metab 12: 308-314.

2. Tanabe A, Naruse M, Naruse K, Hase M, Yoshimoto T, Tanaka M, Seki T, Demura R, Demura H (1997) Left ventricular hypertrophy is more prominent in patients with primary aldosteronism than in patients with other types of secondary hypertension. Hypertens Res 20: 85-90.

3. Rossi GP, Sacchetto A, Pavan E, Palatini P, Graniero GR, Canali C, Pessina AC (1997) Remodeling of the left ventricle in primary aldosteronism due to Conn's adenoma. Circulation 95: 1471-1478.

4. Shigematsu Y, Hamada M, Okayama H, Hara Y, Hayashi Y, Kodama K, Kohara K, Hiwada K (1997) Left ventricular hypertrophy precedes other target-organ damage in primary aldosteronism. Hypertension 29: 723-727.

5. Nishimura M, Uzu T, Fujii T, Kuroda S, Nakamura S, Inenaga T, Kimura G (1999) Cardiovascular complications in patients with primary aldosteronism. $\mathrm{Am} \mathrm{J}$ Kidney Dis 33: 261-266.

6. Gordon RD, Stowasser M, Tunny TJ, Klemm SA, Rutherford JC (1994) High incidence of primary aldosteronism in 199 patients referred with hypertension. Clin Exp Pharmacol Physiol 21: 315-318.

7. Lim PO, Rodgers P, Cardale K, Watson AD, MacDonald TM (1999) Potentially high prevalence of primary aldosteronism in a primary-care population. Lancet 353: 40.

8. Loh K-C, Koay ES, Khaw M-C, Emmanuel SC, Young WF Jr (2000) Prevalence of primary aldosteronism among Asian hypertensive patients in Singapore. J Clin Endocrinol Metab 85: 2854-2859.

9. Gallay BJ, Ahmad S, Xu L, Toivola B, Davidson RC (2001) Screening for primary aldosteronism without discontinuing hypertensive medications: plasma aldosterone-renin ratio. Am J Kidney Dis 37: 699-705.

10. Omura M, Saito J, Yamaguchi K, Kakuta Y, Nishikawa T (2004) Prospective Study on the Prevalence of secondary hypertension among hypertensive patients visiting a general outpatient clinic in japan. Hypertens Res 27: 193-202.

11. Ganguly A (1998) Primary aldosteronism. $N$ Engl J Med 339: 1828-1834.

12. Sasano H, Miyazaki S, Sawai T, Sasano N, Nagura H, Funahashi H, Aida M, Demura H (1992) Primary pigmented nodular adrenocortical disease (PPNAD): Immunohistochemical and in situ hybridization analysis of steroidogenic enzyme in eight cases. Mod Pathol 5: 23-29.

13. Sasano H (1992) New approaches in human adrenocortical pathology: Assessment of adrenocortical function in surgical specimen of human adrenal glands. Endocr Pathol 3: 4-13.

14. Omura M, Sasano H, Fujiwara T, Yamaguchi K, Nishikawa T (2002) Unique cases of unilateral hyperaldosteronemia due to multiple adrenocortical micronodules, which can only be detected by selective adrenal venous sampling. Metabolism 51: 350-355.

15. Hiramatsu K, Yamada T, Yukimura Y, Komiya I, Ichikawa $\mathrm{K}$, Ishihara $\mathrm{M}$, Nagata $\mathrm{H}$, Izumiyama $\mathrm{T}$ (1981) A screening test to identify aldosterone-producing adenoma by measuring plasma renin activity: results in hypertensive patients. Arch Intern Med 141: 1589-1593.

16. Mulatero P, Rabbia F, Milan A, Paglieri C, Morello F, Chiandussi L, Veglio F (2002) Drug effects on aldosterone/plasma renin activity ratio in primary aldosteronism. Hypertension 40: 897-902.

17. Mulatero P, Stowasser M, Loh K-C, Fardella CE, Gordon RD, Mosso L, Gomez-Sanchez CE, Veglio F, Young WF Jr (2004) Increased diagnosis of primary aldosteronism, including surgically correctable forms, in centers from five continents. J Clin Endocrinol Metab 89: 1045-1050.

18. Sato A, Saruta T (2004) Aldosterone-induced organ damage: Plasma aldosterone level and inappropriate salt status. Hypertens Res 27: 303-310.

19. Horita $Y$, Inenaga $T$, Nakahama H, Ishibashi-Ueda $H$, Kawano Y, Nakamura S, Horio T, Okuda N, Ando M, Takishita S (2001) Cause of residual hypertension after adrenalectomy in patients with primary aldosteronism. Am J Kidney Dis 37: 884-889.

20. Young WF Jr (2002) Primary aldosteronism management issues. Ann NY Acad Sci 970: 61-76.

21. Sasamura H, Hashimoto S, Kuribayashi S, Ueno K, Takase A, Hayashi M, Saruta T (2004) Use of gadolinium contrast adrenal venography for the assessment of primary aldosteronism in a patient with iodine allergy. Endocr J 51: 487-492.

22. Doppman JL, Gill JR Jr (1996) Hyperaldosteronism: sampling the adrenal veins. Radiology 198: 309-312.

23. Young WF Jr, Stanson AW, Grant CS, Thompson GB, van Heerden JA (1996) Primary aldosteronism: adrenal venous sampling. Surgery 120: 913-920.

24. Magill SB, Raff H, Shaker JL, Brickner RC, Knechtges TE, Kehoe ME, Findling JW (2001) Comparison of adrenal vein sampling and computed tomography in the differentiation of primary aldosteronism. J Clin Endocrinol Metab 86: 1066-1071.

25. Tanabe A, Naruse M, Machida H, Watanabe D, Tsuiki M, Ueno E, Isobe Y, Takano K (2004) Does ACTH stimulation improve diagnostic significance of adrenal venous sampling in lateralizing primary aldosteronism? J Tokyo Women Med Univ 74: 89-93 (in Japanese). 